Original Scientific Article

\title{
VISIBLY MARKED AND MICROCHIPPED LOST DOGS HAVE A HIGHER CHANCE TO FIND THEIR OWNERS IN BELGRADE
}

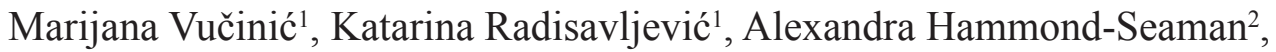 \\ Vlatko Ilieski ${ }^{3}$ \\ ${ }^{1}$ Department of Animal Hygiene, Faculty of Veterinary Medicine, \\ University of Belgrade, Belgrade, Serbia \\ ${ }^{2}$ Royal Society for the Prevention of Cruelty to Animals, Horsham, United Kingdom \\ ${ }^{3}$ Department of Functional Morphology, Faculty of Veterinary Medicine, \\ "Ss. Cyril and Methodius" University in Skopje, Republic of Macedonia
}

Received 3 July 2014; Received in revised form 24 November 2014; Accepted 30 November 2014

\begin{abstract}
The aim of the study was to analyse the demographic characteristics of lost and found dogs in Belgrade, Serbia. The demographic data concerning the 246 lost and 81 found dogs in the period of 5 consecutive years (January, 2009 to January 2014) was sampled and analysed from the data bases of four organizations for animal protection in Belgrade. The recovery rate of lost dogs and the chance to be reunited again with their owners was $33 \%$. The highest recovery rate was estimated in the category of lost dogs with visible marks such as tags or collars (30\%). The chi-square test disclosed that besides dogs with special visible marks, significantly more females, light colour coated, friendly/sociable and neutered dogs were reunited with their owners $(\mathrm{P}<0.0001)$.
\end{abstract}

Key words: demographic characteristics, dog, found, lost

\section{INTRODUCTION}

People have many reasons for owning dogs. For some owners dogs are companions, friends, family members or even children (1-5). For others dogs are toys, status symbols, and brands (6). There are many emotional, mental, physical, therapeutic and social benefits of dog ownership $(4,7,8)$. However, for some owners, the behaviour of their pets may be problematic and consequences of such behaviour may be stressful for both of them. Examples of this may be disobedience, escaping, chasing, running away or dog roaming $(9,10)$. There is scientific evidence that smaller dogs

Corresponding author: Prof. Marijana Vučinić, PhD E-mail address: vucinicm@vet.bg.ac.rs

Present address: Department of Animal Hygiene

Faculty of Veterinary Medicine, University of Belgrade

Bul. Oslobodjenja 18, 11000 Belgrade, Serbia

Phone: +381 113685436

Copyright: (C) 2015 Vucinic M. This is an open-access article published under the terms of the Creative Commons Attribution License which

permits unrestricted use, distribution, and reproduction in any medium, provided the original author and source are credited.

Competing Interests: The authors have declared that no competing

interests exist.

Available Online First: 3 December 2014

http://dx.doi.org/10.14432/j.macvetrev.2014.12.035 are seen as less obedient, more aggressive and excitable and more anxious and fearful (11). All of these may be reasons for dogs to become lost. Besides disobedient dogs, improperly trained dogs of unskilled, inexperienced or irresponsible owners could be lost, too. Additionally, senior and geriatric dogs with weak senses of smell, vision or hearing and possibly with canine cognitive dysfunction syndromes may become lost. Lost dogs may cause great emotional distress to owners. Similarly, lost dogs may be frightened, unsure, hungry and thirsty, mentally and physically exhausted, poisoned, ill or injured as victims of traffic accidents, unfamiliar and aggressive dogs or unfamiliar and malicious people. Also, lost dogs may end up impounded in shelters where they may be reunited with its owner, adopted by a new owner or euthanized (12).

Many dogs are lost due to the irresponsibility of their owners who allow them to roam freely without their supervision or who refuse to spay/neuter or mark pets with microchips or visible tags $(13,14)$. Visible marks such as identification tags with data for the lost dog owner can assure that lost dogs are quickly reunited with their owners $(15,16)$. Many 
strays are lost dogs that were not kept properly indoors or provided with identification. It is well known that responsible dog ownership behaviours include confinement, registration, microchipping, desexing, participation in formal obedience training, and regular socialization practices (14). Also, it is well known that a neutered pet is less likely to roam. Forgetful owners can leave gates or doors open. Moreover, thefts are also common reasons for this stressful interruption of dog-owner relationship (17).

Published data on frequency of lost dogs and cats, search and identification methods that owners use to find them, methods that people use to find owners of lost pets, demographic data of lost pets and owners comes from the United States of America (18, 19, $20)$. Very high recovery rates $(93 \%)$ and reunions with owners were estimated for dogs (20).

Institution of a responsible dog-owner relationship is not well established and supervised in Belgrade, the capital of Serbia. The main consequence of this failure is the great population of stray dogs. It is very difficult to find lost pets among many exteriorly similar stray dogs,. The aim of the study was to examine the demographic data of lost and found dogs and their influence on recovery rates in Belgrade.

\section{MATERIAL AND METHODS}

There are several methods for owners to report the loss of their dogs in Belgrade. Among them, owners can report the loss of their dogs to the municipal agency for stray dog control, veterinary clinics or to animal protection societies. On that occasion, the owners of lost dogs fill out a questionnaire form that contains the contact details of owners and the demographic data concerning the dogs. Owners of lost dogs report breed, gender, age, size, coat colour, special visible marks, microchip number, behaviour characteristics and sex status of their dogs. In Belgrade, lost dogs can be found by their owners, other citizens, and the municipal agency for stray dog control or by members of animal protection societies. The finding of a lost dog could be reported to the municipal agency for stray dog control, the nearest veterinary clinic or to an animal protection society. They put the information of found dogs in their data bases and interchange them.

For the purpose of the study, demographic data concerning 246 lost and 81 found dogs in the period of 5 consecutive years (January, 2009 to January 2014) was sampled and analysed from data bases of four organizations for animal protection in Belgrade. The demographic data on lost and 80 found dogs included breed (purebred/mongrel), gender (female/male), age (puppy to adult/mature to geriatric), size (small to medium/large), coat colour (dark/light), special visible marks, tags or collars (yes/no), microchipped (yes/no) and behaviour (friendly or sociable/fearful or aggressive) and sex status (intact/neutered).

Results are given in absolute values (N), percentages (\%) and 95\% confidence interval $(95 \%$ CI). Statistical significance of proportions of lost and found dogs between different demographic characteristics was estimated by Chi-square test $(\chi 2)$ for binomial frequencies with Yates correction using a $2 \times 2$ contingency table. Values of $\mathrm{P}<0.05$ were considered significant. Recovery/success rate for found dogs (\%) was calculated regarding to the total number of lost dogs $(\mathrm{N}=246)$. All computations were performed using online statistical software GraphPad QuickCalcs.

\section{RESULTS}

Results from the demographic data of lost, found and not found dogs are given in Table 1. In the reference period, 246 owners reported the loss of their dogs to four organizations for animal protection. They more frequently reported the loss of young to adult (82\%), small to medium (78\%), microchipped (77\%), intact (68\%), male (67\%), purebred $(60 \%)$, friendly/sociable animals $(56 \%)$, dogs without special visible marks such as tags or collars (56\%) and dogs with dark coat colour (55\%). Eighty-one dogs were found and returned to their owners. Therefore, the success rate for finding dogs was $33 \%$. The highest recovery and success rate was estimated in the category of dogs identified with special visible marks $(30 \%)$ followed by the category of microchipped (28\%), young to adult (28\%), friendly/sociable $(27 \%)$, small to medium $(26 \%)$ and dogs with light coat colour (26\%). The organizations for animal protection did not find 165 animals (67\%) that previously have been reported as lost dogs by their owners. The Chi-square test disclosed that special visible marks $(\chi 2=99.973)$, sex status $(\chi 2=83.710)$, coat color $(\chi 2=51.425)$, behaviour $(\chi 2=33.151)$ and gender $(\chi 2=18.328)$ could be consider as extremely significant $(\mathrm{P}<0.0001)$ characteristics of lost dogs that affect their fate to be found. Breed $(\chi 2=5.019 ; P=0.0251)$ and the identification method with microchip ( $\chi 2=4.063 ; P=0.0438$ ) could be considered as significant characteristics associated with the finding of lost dogs. Chi-square test did not find the significant association between the lost and found dogs regarding their age and size. 
Visibly marked and microchipped lost dogs in Belgrade

Table 1. Demographic data of lost, found and not found dogs

\begin{tabular}{|c|c|c|c|c|c|c|c|c|c|c|c|c|}
\hline \multirow{2}{*}{ Characteristic } & \multirow{2}{*}{ Category } & \multicolumn{3}{|c|}{$\begin{array}{l}\text { Lost dogs } \\
\mathrm{N}=246\end{array}$} & \multicolumn{3}{|c|}{$\begin{array}{l}\text { Found dogs } \\
\qquad \mathrm{N}=81\end{array}$} & \multicolumn{3}{|c|}{$\begin{array}{l}\text { Not found dogs } \\
\qquad N=165\end{array}$} & \multirow{2}{*}{$\chi^{2}$} & \multirow{2}{*}{$P$} \\
\hline & & $\mathrm{n}$ & $\%$ & $95 \% \mathrm{CI}$ & $\mathrm{n}$ & $\begin{array}{l}\text { Recovery } \\
\text { rate } \%\end{array}$ & $95 \% \mathrm{CI}$ & $\mathrm{n}$ & $\%$ & $95 \% \mathrm{CI}$ & & \\
\hline \multirow{2}{*}{ Breed } & Purebred & 147 & 60 & $54-66$ & 57 & 23 & $18-29$ & 90 & 37 & $31-43$ & \multirow{2}{*}{5.019} & \multirow{2}{*}{$=0.0251$} \\
\hline & Mixed bred & 99 & 40 & $34-46$ & 24 & 10 & $6-14$ & 75 & 30 & $25-37$ & & \\
\hline \multirow{2}{*}{ Gender } & Male & 165 & 67 & $61-73$ & 39 & 16 & $12-21$ & 126 & 51 & $45-57$ & \multirow{2}{*}{18.328} & \multirow{2}{*}{$<0.0001$} \\
\hline & Female & 81 & 33 & $27-39$ & 42 & 17 & $13-22$ & 39 & 16 & $12-21$ & & \\
\hline \multirow[b]{2}{*}{ Age } & Young to adult & 201 & 82 & $76-86$ & 69 & 28 & $23-34$ & 132 & 54 & $47-60$ & \multirow[b]{2}{*}{0.661} & \multirow[b]{2}{*}{$=0.4162$} \\
\hline & $\begin{array}{l}\text { Mature to } \\
\text { geriatric }\end{array}$ & 45 & 18 & $14-24$ & 12 & 5 & $3-8$ & 33 & 13 & $3-9$ & & \\
\hline \multirow[t]{2}{*}{ Size } & $\begin{array}{l}\text { Small to } \\
\text { medium }\end{array}$ & 192 & 78 & $72-83$ & 63 & 26 & $21-31$ & 129 & 52 & $46-59$ & \multirow[t]{2}{*}{0.005} & \multirow[t]{2}{*}{$=0.9426$} \\
\hline & Large & 54 & 22 & $17-28$ & 18 & 7 & $5-11$ & 36 & 15 & $11-20$ & & \\
\hline \multirow{2}{*}{ Hair color } & Dark & 136 & 55 & $49-61$ & 18 & 7 & $5-11$ & 118 & 48 & $42-54$ & \multirow[b]{2}{*}{51.425} & \multirow[b]{2}{*}{$<0.0001$} \\
\hline & Light & 110 & 45 & $39-51$ & 63 & 26 & $21-31$ & 47 & 19 & $15-25$ & & \\
\hline \multirow{2}{*}{$\begin{array}{l}\text { Special } \\
\text { visible marks }\end{array}$} & Yes & 109 & 44 & $38-51$ & 73 & 30 & $24-36$ & 36 & 15 & $11-20$ & \multirow{2}{*}{99.973} & \multirow{2}{*}{$<0.0001$} \\
\hline & No & 137 & 56 & $49-62$ & 8 & 3 & $2-6$ & 129 & 52 & $46-59$ & & \\
\hline \multirow{2}{*}{ Microchipped } & Yes & 189 & 77 & $71-82$ & 69 & 28 & $23-34$ & 120 & 49 & $43-55$ & \multirow{2}{*}{4.063} & \multirow{2}{*}{$=0.0438$} \\
\hline & No & 57 & 23 & $18-29$ & 12 & 5 & $3-8$ & 45 & 18 & $14-24$ & & \\
\hline \multirow{2}{*}{ Behaviour } & $\begin{array}{l}\text { Friendly/ } \\
\text { Sociable }\end{array}$ & 138 & 56 & $50-62$ & 67 & 27 & $22-33$ & 71 & 29 & $24-35$ & \multirow{2}{*}{33.151} & \multirow{2}{*}{$<0.0001$} \\
\hline & $\begin{array}{l}\text { Fearful/ } \\
\text { Aggressive }\end{array}$ & 108 & 44 & $38-50$ & 14 & 6 & $3-9$ & 94 & 38 & $32-44$ & & \\
\hline \multirow{2}{*}{ Sex status } & Intact & 167 & 68 & $62-73$ & 23 & 9 & $6-14$ & 144 & 59 & $53-65$ & 83710 & $<00001$ \\
\hline & Neutered & 79 & 32 & $27-38$ & 58 & 24 & $19-29$ & 21 & 8 & $6-13$ & (1) & 0.0001 \\
\hline Found doos & Yes & 81 & 33 & $27-39$ & & & & & & & & \\
\hline r vand aogs & No & 165 & 67 & $61-73$ & & & & & & & & \\
\hline
\end{tabular}

\section{DISCUSSION}

There are a great number of stray dogs in Belgrade. Lost dogs are included in the population of stray dogs. Different attempts and methods to control the population of stray dogs were implemented in Belgrade. CNR method (CNR Catch-Neuter-Release) is one of them. The method includes spaying/neutering, identification with a microchip and anti rabies vaccination of dogs after which they are released back on the streets and habitats where they continue to live under the protection of keepers. The term "keeper" means a person who takes care of a stray dog in the place where he or she lives and provides food, water and veterinary care for that animal. These dogs are not visibly marked. Belgrade residents are interested in the adoption of stray dogs from municipal or private shelters, so many strays find new owners and homes. Also, some irresponsible owners allow their pets to roam freely in public places. Residents are accustomed to the presence of stray dogs on the streets of Belgrade. Therefore, it is normal to assume that they are not able to make a difference between strays and lost dogs if the last of them are not visibly marked. It may be one of the reasons for the low percentage of successfully finding lost dogs. In this study, the highest recovery rate was estimated in the category of lost dogs with special visible marks such as tags or collars. American authors (16) especially emphasized the important role of veterinarians in the protection of pets, as well as pet owners and the human-animal bond by integrating pet identification into preventive health care. In our study the recovery rate for found dogs of all categories was $33 \%$. This is a much lower value compared to the recovery rate $(93 \%)$ in the US where many of lost dogs were visibly marked with tags or collars (20). For microchipped dogs in our study the recovery rate was high, too (28\%). Other authors also found that lost dogs with identification tags or microchips are more likely to be reunited than those without $(13,15)$. Lost pets with identification microchips were up to 21 times more likely to be reunited than those without (16). In the population of lost dogs in Belgrade there were $32 \%$ of neutered dogs and th success rate to be reunited with their owners was $24 \%$. The low percentage of neutered dogs was estimated in the population of owned dog in other countries such as in Guatemala and 
Italy $(21,22)$. In our study the higher success rate to be reunited with owners was estimated in the category of purebred, young to adult dogs, small to medium and friendly/sociable dogs as compared with opposite characteristics of lost dogs. It was previously estimated that dogs' features (bred, age, size) strongly affect people's feelings and behavior toward them $(23,24,25)$. Our results suggest that individuals in Belgrade who found lost dogs tended to interact with these categories of dogs, so that they were more likely to be found than mixed bred, mature to geriatric, large or fearful/aggressive dogs. However, we have not found significant association between the lost and found dogs with regard to their age and size. It is possible that some demographic characteristics interacted and so jointly affected the fate of lost dogs to be found. This will be the subject of our further studies. Analysis of demographic data of lost dogs in Belgrade disclosed that in this population $78 \%$ were small to medium dogs. Investigation of other authors confirmed that smaller dogs are seen as less obedient, more aggressive, excitable, anxious and fearful than larger dogs (11). Some of those behaviours were related to a more frequent use of punishment in smaller, but not in larger dogs. However, their recovery rate in our study was high $(26 \%)$. It is also possible that people from Belgrade are afraid of large dogs and this assumption can be one of explanation for their lower recovery rate $(7 \%)$. One of the explanations for the high percentage of found dogs with light coat colour and purebred dogs in our study can be their exterior differences from the uniform population of stray dogs in Belgrade. In other words, it is possible that these dogs were easily recognizable than mongrels and dogs with dark coat colour by people in the streets of Belgrade. Other authors who studied the impact of different dog features on humans in public observed that large-dark dogs seemed to be more threatening than pale or small dogs (23). At the same time it is well known that in some societies large dark coated dogs are adopted less frequently and euthanized more frequently than dogs of other sizes and colours. It is so called "Big Black Dog Syndrome" (26). During investigation of "Black Dog Syndrome" in Poland, it was estimated that black dogs were adopted more frequently than dogs of other colours (27).

\section{CONCLUSION}

It was the first survey in Serbia on the population of lost dogs. Such investigations can be of great importance for veterinarians, dog breeders and kennel experts, because they can serve as a 82 guideline to them how to advise or educate dog owners about the importance of dog identification by microchips or visible marks, neutering, obedience training and socialization of dogs. On the other hand, results of this study may serve to members of non-governmental organizations and other citizens looking for lost dogs with regards to their characteristics. Finally, the results of this study alert us to the extremely high number of lost dogs in Belgrade and a low percentage of their recovery rate. Therefore, these results should stimulate us to raise the responsibility of dog owners, their knowledge and skills of handling dogs and preventing the loss of the dogs. Although, identification by microchips is the best method to increase recovery rate of lost dogs, their finding and collection should be done by professionals on a 24 hour basis and not left to inexperienced citizens.

\section{REFERENCES}

1. Archer, J. (1997). Why do people love their pets? Evol Hum Behav, 1, 8, 237-259. http://dx.doi.org/10.1016/S0162-3095(99)80001-4

2. Cohen, S.P. (2002). Can pets function as family members. Western J Nurs Res, 24, 621-638. http://dx.doi.org/10.1177/019394502320555386

3. Dotson, J. M., Hyatt, M. E. (2008). Understanding dog-human companionship. J Bus Res, 61, 457-466. http://dx.doi.org/10.1016/j.jbusres.2007.07.019

4. Friedmann, E., Son, H. (2009). The humancompanion animal bond: How humans benefit. Vet Clin North Am Small Anim Pract, 39, 293-326. http://dx.doi.org/10.1016/j.cvsm.2008.10.015 PMid:19185195

5. Mosteller, J. (2008). Animal-companion extremes and underlying consumer themes. J Bus Res, 61, 512-521. http://dx.doi.org/10.1016/j.jbusres.2007.07.004

6. Beverland, B. M., Farrelly, F., Lim, E. A. C. (2008). Exploring the dark side of pet ownership: Status and control-based pet consumption. J Bus Res, 61, 490-496.

http://dx.doi.org/10.1016/j.jbusres.2006.08.009

7. Knight, S. (2008). In the company of wolves: The physical, social, and psychological benefits of dog ownership. J Aging Health, 20, 437-455.

http://dx.doi.org/10.1177/0898264308315875 PMid:18448686

8. McConnell, R. A., Brown, M. C., Shoda, M. T., Stayton, E. L., Colleen, E. M. (2011). Friends with benefits: On the positive consequences of pet ownership. J Pers Soc Psychol, 101, 1239-1252. http://dx.doi.org/10.1037/a0024506 PMid:21728449 
Visibly marked and microchipped lost dogs in Belgrade

9. Jagoe, A., Serpell, J. (1996). Owner characteristics and interactions and the prevalence of canine behaviour problems. Appl Anim Behav Sci, 47, 31-42. http://dx.doi.org/10.1016/0168-1591(95)01008-4

10. Bennett, C. P., Rohlf, I. V. (2007). Owner-companion dog interactions: Relationships between demographic variables, potentially problematic behaviours, training engagement and shared activities. Appl Anim Behav Sci, 102, 65-84. http://dx.doi.org/10.1016/j.applanim.2006.03.009

11. Arhant, C., Bubna-Littitz, H., Bartels, A., Futschik, A., Troxler, J. (2010). Behaviour of smaller and larger dogs: Effects of training methods, inconsistency of owner behaviour and level of engagement in activities with the dog. Appl Anim Behav Sci, 123, 131-142. http://dx.doi.org/10.1016/j.applanim.2010.01.003

12. Lepper, M., Kass, P. H., Hart, L. A. (2002). Prediction of adoption versus euthanasia among dogs and cats in a California animal shelter. J Appl Anim Welf Sci, 5, 29-42.

http://dx.doi.org/10.1207/S15327604JAWS0501_3 PMid:12738587

13. Lord, K. L., Ingwersen, W., Gray, L. J., Wintz , J. D. (2009). Characterization of animals with microchips entering animal shelters. J Am Vet Med Assoc, 235, 160-167.

http://dx.doi.org/10.2460/javma.235.2.160

PMid:19601734

14. Rohlf, V. I., Bennett, P. C., Toukhsati, S. (2010). Why do even committed dog owners fail to comply with some responsible ownership practices? Anthrozoos 23, 143-155.

http://dx.doi.org/10.2752/175303710X12682332909972

15. Weiss, E., Slater, M., Lord, L. (2011). Retention of provided identification for dogs and cats seen in veterinary clinics and adopted from shelters in Oklahoma City, OK, USA. Prev VetMed, 101,301-315. http://dx.doi.org/10.1016/j.prevetmed.2011.05.008 PMid:21704398

16. Dingman, P., Levy, J., Rockey, L., Crandal, M. (2014). Use of visual and permanent identification for pets by veterinary clinics. Vet J, 201, 46-50.

http://dx.doi.org/10.1016/j.tvj1.2014.04.024

PMid:24907866

17. Houpt, K.A., Goodwin, D., Uchida, Y., Baranyiová, E., Fatjó, J., Kakuma, Y. (2007). Proceedings of a workshop to identify dog welfare issues in the US, Japan, Czech Republic, Spain and the UK. Appl. Anim Behav Sci, 106, 221-233. http://dx.doi.org/10.1016/j.applanim.2007.01.005
18. Lord, L. K., Wittum, E. T., Ferketich, K. A., Funk, A. J, Rajala-Schultz, J. P. (2007). Search and identification methods that owners use to find a lost dog. J Am Vet Med Assoc, 230, 211-216. http://dx.doi.org/10.2460/javma.230.2.211 PMid:17223753

19. Lord, L., Wittum, E. T., Ferketich, K. A., Funk, A. J, Rajala-Schultz, J. P. (2007). Search methods that people use to find owners of lost pets. J Am Vet Med Assoc, 230, 1835-1840.

http://dx.doi.org/10.2460/javma.230.12.1835

PMid:17571985

20. Weiss, E., Slater, M., Lord, L. (2012). Frequency of lost dogs and cats in the United States and the methods used to locate them. Animals 2, 301-315. http://dx.doi.org/10.3390/ani2020301

21. Pulczer, S. A., Jones-Bitton, A., Waltner-Toews, D., Dewey, E. C. (2013). Owned dog demography in Todos Santos Cuchumatán, Guatemala. Prev Vet Med, 108, 209-217.

http://dx.doi.org/10.1016/j.prevetmed.2012.07.012 PMid:22906504

22. Slater, R. M., Di Nardo, A., Pediconi, O., Dalla Villa, P., Candeloro, L., Alessandrini, B., Del Papa, S. (2008). Cat and dog ownership and management patterns in central Italy. Prev Vet Med, 85, 267-294. http://dx.doi.org/10.1016/j.prevetmed.2008.02.001 PMid:18374434

23. Blecker, D., Hiebert, N., Kuhne, F. (2013). Preliminary study of the impact of different dog features on humans in public. J Vet Behav, 8, 170-174. http://dx.doi.org/10.1016/j.jveb.2012.06.005

24. Gazzano, A., Zilocchi, M., Mariti, C. (2013). Dogs' features strongly affect people's feelings and behavior toward them. J Vet Behav, 8, 213-220. http://dx.doi.org/10.1016/j.jveb.2012.10.005

25. Cannas, S., Rampini, F., Levi, D., Costa ED., Talamonti, Z., Minero, M., Palestrini, C. (2014). Shelter dogs and their destiny. A retrospective analysis to identify predictive factors - a pilot study. Mac Vet Rev, 37, 151-156. http://dx.doi.org/10.14432/j.macvetrev.2014.07.018

26. Leonard, A. (2011). The plight of "Big black dogs" in American animal shelters: Color-based canine discrimination. Pap Kroeber Anthropol Soc, 99, 168-183.

27. Goleman, M., Drozd, L., Karpinski, M., Czyzowski, P. (2014). Black dog syndrome in animal shelters. Med Weter, 70, 122-127. 